\title{
A new multidimensional population health indicator for policy makers: absolute level, inequality and spatial clustering - an empirical application using global sub-national infant mortality data
}

\author{
Benn K.D. Sartorius ${ }^{1,2}$, Kurt Sartorius ${ }^{3}$ \\ ${ }^{1}$ Discipline of Public Health Medicine, School of Nursing and Public Health, University of KwaZulu-Natal, \\ Durban, South Africa; ${ }^{2}$ School of Public Health, Faculty of Health Sciences, University of the Witwatersrand, \\ Johannesburg, South Africa; ${ }^{3}$ Faculty of Commerce, Law and Management, University of the Witwatersrand, \\ Johannesburg, South Africa
}

\begin{abstract}
The need for a multidimensional measure of population health that accounts for its distribution remains a central problem to guide the allocation of limited resources. Absolute proxy measures, like the infant mortality rate (IMR), are limited because they ignore inequality and spatial clustering. We propose a novel, three-part, multidimensional mortality indicator that can be used as the first step to differentiate interventions in a region or country. The three-part indicator (Mortality ${ }_{\mathrm{ABC}}$ index) combines absolute mortality rate, the Theil Index to calculate mortality inequality and the Getis-Ord $\mathrm{G}$ statistic to determine the degree of spatial clustering. The analysis utilises global sub-national IMR data to empirically illustrate the proposed indicator. The three-part indicator is mapped globally to display regional/country variation and further highlight its potential application. Developing countries (e.g. in sub-Saharan Africa) display high levels of absolute mortality as well as variable mortality inequality with evidence of spatial clustering within certain sub-national units ("hotspots"). Although greater inequality is observed outside developed regions, high mortality inequality and spatial clustering are common in both developed and developing countries. Significant positive correlation was observed between the degree of spatial clustering and absolute mortality. The proposed multidimensional indicator should prove useful for spatial allocation of healthcare resources within a country, because it can prompt a wide range of policy options and prioritise high-risk areas. The new indicator demonstrates the inadequacy of IMR as a single measure of population health, and it can also be adapted to lower administrative levels within a country and other population health measures.
\end{abstract}

Keywords: population health indicator, mortality level, inequality, spatial clustering.

\section{Introduction}

The inequality debate, recently raised by the Nobel laureate, Joseph Stiglitz (Stiglitz, 2012), has triggered a new interest in this phenomenon and its impact on public health. In effect, it can be argued that healthcare expenditure in many countries disproportionally favours the rich at the expense of the poor. Skewed access to healthcare, therefore, can be linked to a social determinant that can negatively impact the health of a majority of citizens in many countries (Deaton, 2013). Although the impact of inequality is well recorded as a social determinant of mortality

\section{Corresponding author:}

Benn Sartorius

George Campbell Building, $2^{\text {nd }}$ floor

Howard College Campus, Discipline of Public Health Medicine School of Nursing and Public Health, College of Health Sciences University of KwaZulu-Natal, Durban, South Africa, 4041

Tel. +27 31 260-4459; Fax +27 31 260-4211

E-mail: sartorius@ukzn.ac.za
(Wilkinson, 1992; Marmot, 2005), little research has investigated spatial mortality inequality in a global and national context. Recently there has been renewed interest in social and geographical inequality as evidenced by the expanding literature in this area (Goldthorpe, 2010; Anselmi et al., 2013).

A projection of global health outcomes from 2005 to 2060 reflect changing patterns of mortality across the globe (Hughes et al., 2011) and provides a sense of the changing nature of this phenomenon over the last century (Murray and Lopez, 1997; Obermeyer et al., 2010; Rajaratnam et al., 2010). Despite a general global trend of reduced mortality, persistent clusters of high mortality are still found in many developing countries (Murray, 1996; Murray and Lopez, 1997; Houweling et al., 2001; Rajaratnam et al., 2010). Intra-country mortality inequality remains a problematic issue in both developed and developing countries (Houweling et al., 2001, 2005; McMichael et al., 2004) and national-level analyses remain crude and unable to quantify subnational variation (Storeygard et al., 2008). Interestingly, richer 
countries with lower levels of absolute mortality continue to grapple with the mortality inequality divide (McMichael et al., 2004; Obermeyer et al., 2010). Simultaneously, the geography of mortality, its level of inequality and dispersion across the globe, will remain a global policy issue that has received little attention since 2000 .

The need for multidimensional measures of health remains a central problem to policy makers (Marmot, 2005) bringing into question the widespread use of absolute mortality level and its trends as a basis to direct policy (Houweling et al., 2005; Rajaratnam et al., 2010). This one-dimensional reliance on absolute mortality is questioned because it ignores the distribution of this phenomenon (Reidpath, 2005). This shortfall is even more problematic when disaggregated measures of mortality, such as infant mortality rate (IMR), are used as a general proxy for overall population health. Although these summary measures can act as a pragmatic guide for policy making (Murray, 2000; Reidpath and Allotey, 2003), they mask multidimensional properties like the degree and spatial location of inequality within and between populations. Two countries, for instance, with the same absolute level of mortality, can have very different levels of mortality inequality that are differentially spatially clustered (Gakidou et al., 2000; Reidpath, 2005). One-dimensional measures (e.g. IMR) are also often problematic because they narrow policy focus and the actions required, as well limit its application to a segment of the population (Murray, 1996; Reidpath and Allotey, 2003; Greenland, 2005). Although there have been initiatives to broaden inequality research beyond economics by measuring health inequality (Wolfson and Rowe, 2001; Murphy et al., 2006; Bessudnov et al., 2012), mortality inequality appears to have been more employed by economists than epidemiologists (Peltzman, 2009). Recent advances in spatial analysis (and software) have also been ignored as a basis to quantify the spatial clustering of health outcomes (Storeygard et al., 2008). The limitation of one-dimensional population health measures appears to be recognised in the 2000 world health report (Coyne and Hilsenrath, 2002) that made little reference to mortality measures like IMR. Given the importance of incorporating health inequality and spatial clustering into policy making (Gakidou et al., 2000; Deaton, 2001), it is an opportune time to develop such a simple multidimensional mortality indicator.

A theory of relative deprivation underpins the concept of mortality inequality (Yitzhaki, 1979) that can be explained as unequal access to a social welfare uti- lity. Various authors argued that inequality would either converge over time (convergence theory) because of the diffusion of technology or expand as a result of increasing polarisation as the rich obtain a greater portion of limited resources (polarisation theory) (Firebaugh, 1999). Recent insights support the contention that inequality has increased because of a widening gap between the rich and the poor thus supporting polarisation theory contentions (Stiglitz, 2012) that can be demonstrated as increasingly unequal access to healthcare resources (Deaton, 2013).

The aim of this paper is to contribute to the inequality debate in the health domain by developing a multidimensional measure of mortality. The proposed measure is a three-part mortality indicator that simultaneously measures absolute mortality, mortality inequality and mortality clustering. The primary focus of this paper is methodological and we use empirical data merely to illustrate an application of the multidimensional mortality measure to evaluate IMR differences by country. We limit our interpretation of the findings to trying to justify that the use of the new measure, as well as verify its accuracy and spatial appeal. The paper makes use of the Theil inequality index (Allison, 1978) for the first time in the public health domain to refine the measurement of mortality inequality or entropy in order to make a contribution to global health policy. The paper also incorporates advances in spatial analytic methods and available software that has created new opportunities to quantify the degree of spatial concentration of mortality inequality ("non-randomness") (Walter, 2000; Rezaeian et al., 2007). Although the paper is motivated by both health and sociological concerns, it does not speak to the social determinants of mortality or mortality inequality that are well documented in the literature (Wilkinson, 1992; Mackenbach et al., 1997; Ezzati et al., 2002; Marmot, 2005; Wilkinson and Pickett, 2006; Rajaratnam et al., 2010).

\section{Materials and methods}

\section{Data sources}

Data were extracted from a number of sources. Overall national IMRs for 2000 were extracted for each country from UNICEF (UNICEF, 2004). Subnational infant mortality data for the inequality and spatial clustering analyses were obtained from the "Global Sub-national Infant Mortality Rates" dataset (CIESIN, 2005). This dataset consists of sub-national estimates of IMRs for the year 2000. Sub-national infant mortality data for 77 countries are available in 
the original dataset. Data were from the period 19962003 for 69 countries. For the other eight countries, data from as early as 1990 were used. A full description of this data source and methods have been published previously (Storeygard et al., 2008). The original dataset did not contain data for 119 countries as they were unable to find a complete collection sub-national IMR (Storeygard et al., 2008). We attempted to supplement this missing sub-national data with data from other demographic and health surveys, national reports/statistics as well as published literature. We found sub-national data for an additional 43 countries (a list of countries for which missing data were supplemented can be found in Appendix 1). If data were not available for the year 2000, we used data from the nearest available year, similarly done for eight countries when producing the original dataset (CIESIN, 2005). The year for which the supplemental data were available can be found in Appendix 1. After supplementation, sub-national data were thus unavailable for 76 countries. A list of the sources or citations for the supplemented data is available on request from the authors.

\section{Proposed mortality indicator}

This section develops a generic, three-part, mortality indicator that is applied to infant mortality data as described above. The three-part indicator, which we represent as the Mortality ${ }_{A B C}$, presents absolute mortality, mortality inequality and spatial clustering of mortality. Absolute mortality was measured as a rate per 1,000 births, mortality inequality was measured using the Theil inequality index and mortality clustering or "non-randomness" was determined using the Getis and Ord local G statistics (Getis and Ord, 1992, 1995). Absolute mortality ranks the country in terms of overall burden, while inequality and spatial clustering are sub-national policy guidance attributes. An example set of decision rules based on the observed multi-attribute permutations are presented in the discussion. The three-part indicator of mortality is then constructed, ranked for each country and also mapped globally. The ranking of Mortality ${ }_{A B C}$ strata was based on the observed IMR (i.e. mean IMR rank within each stratum) and also based on confidence intervals for IMR within each stratum (i.e. non-overlapping strata suggests significant differences between strata in terms of mortality levels).

A. Absolute mortality level - The mortality indicator used should be in line with international norms. In this instance, the IMR is the probability (expressed as a rate per 1,000 live births) of a child born in a specified year dying before reaching the age of one if subject to current age-specific mortality rates. We further split the observed national IMR into three categories, namely high $(\mathrm{H})$, medium $(\mathrm{M})$ and low $(\mathrm{L})$, based on tertiale cut-offs. This analysis was performed in Stata 13.0 SE (StataCorp, 2013).

B. Mortality inequality at sub-national level - As suggested in Reidpath (2005): "If populations can become units of interest in and of themselves, separate from the individual, then interventions can be targeted at characteristics of populations. This has profound implications for what public health can do, and for the allocation of health resources" the fundamental justification for using spatial inequality is that it naturally aligns itself with health administration units and can be more readily used for policy guidance. Targeting unequal units (making the society fairer) may thus benefit population health as a whole, i.e. reduce overall (infant) mortality. A wide range of inequality measures have been developed and widely used in economics to assess differential access to a social welfare utility like income (Firebaugh, 1999). Generally an inequality index ranges between 0 and $1(0 \%$ and $100 \%)$, where 0 indicates perfect equality and $1(100 \%)$ indicates maximum inequality. A more detailed description of the common inequality measures can be found in Appendix 2.

The question remains as to which one of the abovementioned four indexes is the most suited to measure mortality inequality. We chose the Theil index after a set of criteria was reviewed for each of the major inequality indices (see Appendix 3). The rationale for preferring the Theil index is not that there are inherent flaws in the other measures, but that Theil's $\mathrm{T}$ has a more flexible structure that often makes it more appropriate (especially we propose for the health-related outcomes), can estimate inequality over different levels of aggregation and is decomposable (i.e. additive across different subgroups or regions in the country) which is of importance to policy makers. The Gini coefficient is not additive across groups, which is its major disadvantage in this case. Furthermore, the Theil index has less stringent data requirements than the other indices and is more suited to aggregated or grouped data (often more readily available than individual survey data) while the COV and Gini for example are better suited to individual level data (Hale, 2003). We calculated a country-specific Theil inequality value in Stata 13.0 SE (StataCorp, 2013) using the "ineqdeco" module. This module is can be used to calculate inequality indices with decomposition by sub- 
group (Jenkins, 1999). The country specific continuous Theil index score was further reclassified into tertials, namely high (H), medium (M), low (L), for use in the proposed, three-part indicator.

C. Clustering of sub-national mortality: random or non-random "inequality" - commonly used local indicators of spatial autocorrelation (LISA) (Anselin, 1996) are used to identify clusters in the spatial arrangement of a given variable i.e. non-random spatial distribution of mortality in this case. We also used the administrative polygon version of the data for our spatial autocorrelation analysis to avoid errors associated with the grid due to auto-replication (Storeygard et al., 2008). The various types of LISA statistics all have certain advantages and disadvantages. For our universal indictor we choose the Getis \& Ord local G statistic (or $\mathrm{G}_{i}{ }^{*}$ statistic) (Getis and Ord, 1992, 1995) to estimate the strength of spatial autocorrelation of subnational IMR's instead of the commonly used local Moran's I and Geary's C statistics. The reason for this is that, unlike the Moran I and Geary C statistics (Anselin, 1996), the $\mathrm{G}_{i}{ }^{*}$ statistic identifies the degree to which high or low values cluster together. These statistics were calculated using GeoDa software (Anselin et al., 2006). Significance was set at 5\% after 99,999 iterations. The $\mathrm{G}_{i}{ }^{*}$ statistic relates the significance and intensity of clustering to the size of a $Z$ score. For statistically significant positive $Z$ Scores, the larger the $Z$ score is, the more intense the clustering of high values and the converse is true for negative $\mathrm{G}_{i}{ }^{*}$ scores.

The Mortality ${ }_{\mathrm{ABC}}$ indicator was mapped using MapInfo Professional version 9.5 (MapInfo Corporation, 2008).

\section{Results}

\section{Absolute mortality}

The results first evaluated absolute IMR on a global basis using national level estimates. The data suggest a mean national IMR per 1,000 live births of 46.4 (95\% confidence interval $(\mathrm{CI})=40.1-52.7)$. The five highest IMR were observed in Sierra Leone (145.5), Angola (118.7), Democratic Republic of the Congo (117.3), Mozambique (116.0) and Mali (113.9). Conversely, the lowest IMR were observed in Japan (3.3), Sweden (3.4), Finland (3.5), Norway (3.8) and France (4.4).

\section{Mortality inequality}

A high degree of mortality inequality, illustrated in Fig. 1, is evident at the sub-national level when com-

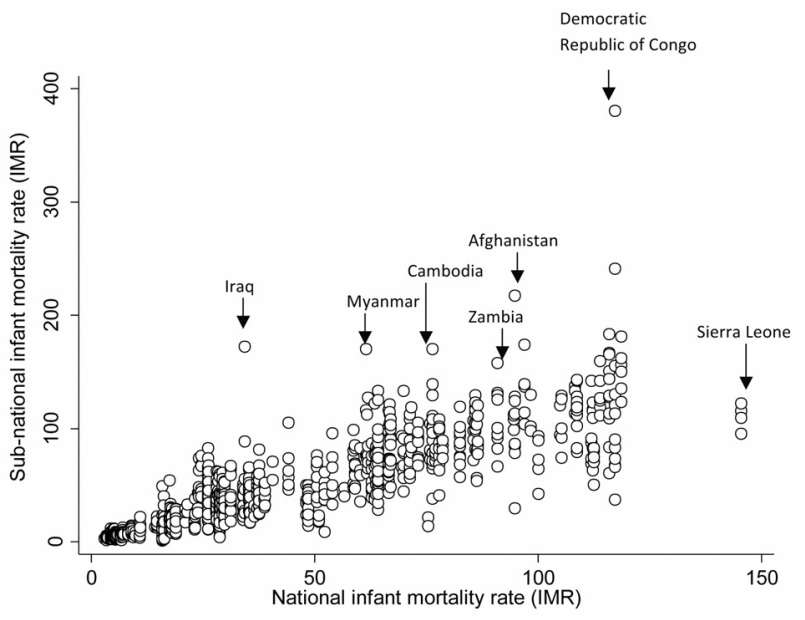

Fig. 1. Scatter plot of overall ascending national IMR versus corresponding sub-national IMR, 2000 (or closest available year).

paring overall national IMR to its sub-national equivalents. Significant outlying or extreme values can be observed within certain countries, for example, Iraq and the Democratic Republic of the Congo are highlighted. A more detailed analysis of global mortality inequality based on sub-national mortality is presented in Fig. 2. The mean global Theil inequality score was 0.037 (95\% CI $=0.029-0.044)$ where the degree of inequality is measured as the distance from a state of perfect equality. Ascending values of the Theil mortality inequality index, therefore, reflect higher levels of mortality inequality (Fig. 2). Initially a linear increasing pattern is observed, but as one moves to the higher inequality countries, we observe a sudden exponential rise. The highest Theil inequality score was observed in Iraq followed by Thailand, Democratic Republic of the Congo and China. Conversely the lowest mortality inequality was observed in Ukraine followed by Japan and Burkina Faso and Swaziland. Comprehensive sub-national data could not be obtained for Ukraine so this may be a spurious finding. Despite low inequality, the absolute mortality level in Burkina Faso was very high $(\mathrm{IMR}=94.6)$ and high in Swaziland (IMR $=77.1$ ) in 2000. No significant correlation was observed between the Theil inequality score and absolute country level IMR (correlation coefficient $(\rho)=-0.04, P>0.1)$.

\section{Mortality clustering}

There did not appear to be any significant correlation between the Theil inequality score and the number of significant local spatial clusters $(\rho=-0.10$, $P>0.1)$. However, we observed significant positive cor- 


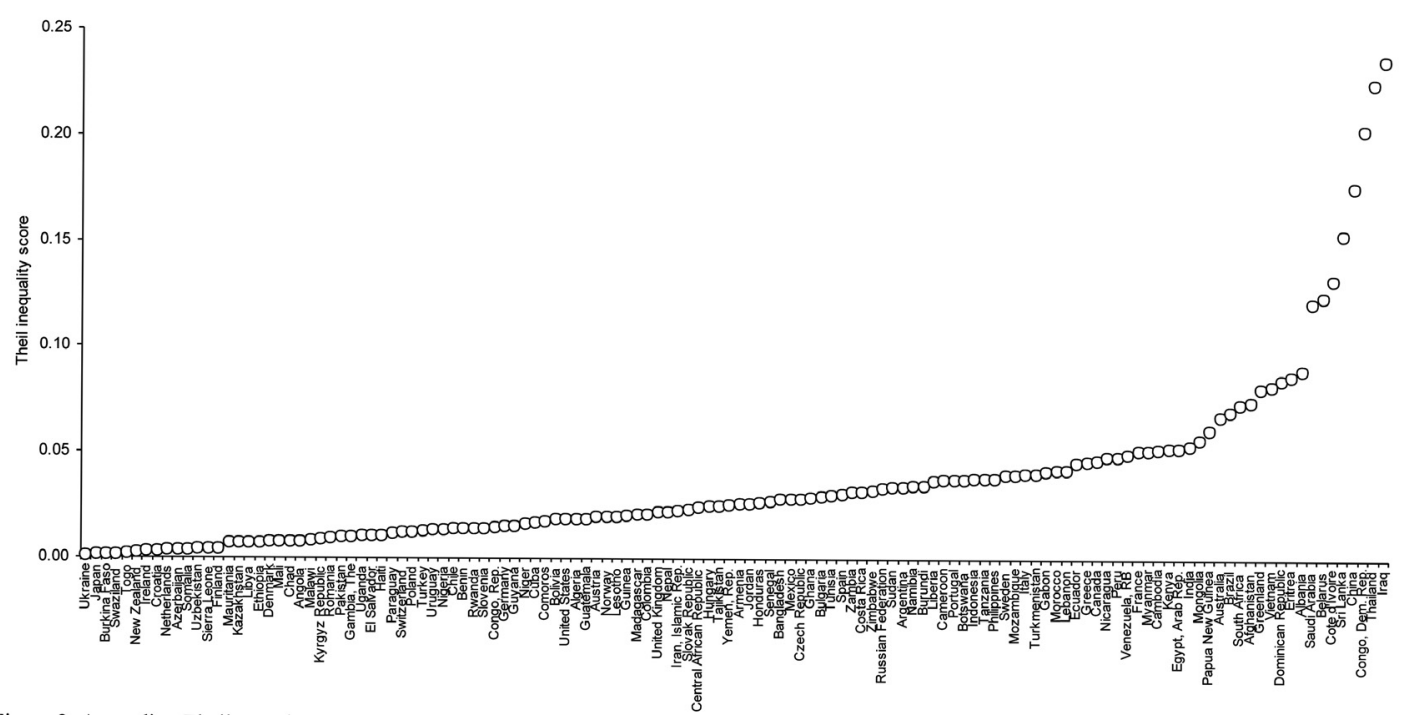

Fig. 2. Ascending Theil IMR inequality score using sub-national data, 2000 (or closest available year).

relation between a number of significant local spatial clusters and the absolute country level IMR $(\rho=0.53$, P-value $<0.01$ ) i.e. high sub-national mortality is likely to be surrounded by other high sub-national mortality. This is graphically depicted in Fig. 3. The IMR among countries where significant sub-national spatial autocorrelation present was significantly higher than those without (mean IMR of 64 versus $28, \mathrm{P}<0.001$ ). The degree of mortality clustering for each country is illustrated in the third component of the multidimensional Mortality ${ }_{\mathrm{ABC}}$ indicator.

\section{The mortality $A B C$ indicator}

This indicator, illustrated in Table 1, ranks each country in terms of permutations of its three-part score $(\mathrm{A}, \mathrm{B}, \mathrm{C})$ as well as provides estimated total population size and infants living within these categories in 2000. The absolute level of mortality (A) is disaggregated into three levels, namely high $(\mathrm{H})$, medium (M) and low (L) and were based on tertiale (33 and 66 percentile) cut-off's for the continuous absolute mortality rate. Similarly, the calculated continuous mortality inequality score (B) is disaggregated into the same three levels based on the tertiale cut-offs for its distribution. To illustrate whether clustering $(\mathrm{C})$ was significant or not an asterisk (*) illustrates significant clustering. The ranking of countries in Table 1 (based on descending mean IMR rank within each strata), suggests that the further one moves towards the bottom on this continuum, the "better" the hypothesised situation. The results indicate, for instance, that Sub-Saharan Africa (SSA), in particular, shows high levels of absolute IMR and significant spatial clu- stering of high mortality. Developing countries within this strata like Sierra Leone, Angola, Mali and Nigeria are all categorised at the top of the table $\left(\mathrm{H}: \mathrm{L}:{ }^{*}\right.$ or "worst" stratum) with approximately 17,970,880 births in this grouping in 2000, the third highest observed in Table 1. Conversely, countries like Iceland, Ireland and New Zealand within the L:L:* stratum (low absolute mortality rates, low levels of mortality inequality but indicate significant spatial clustering) had the lowest IMR rank (Table 1, Fig. 4) and suggest the best case scenario based on the Mortality ${ }_{A B C}$ indicator. This grouping had the lowest estimated number of births in 2000. Fig. 4 further depicts the mean IMR

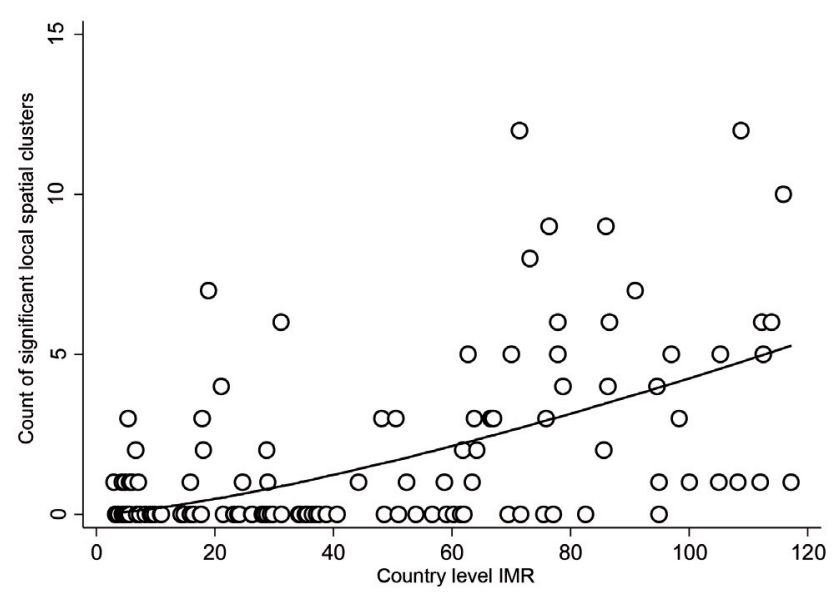

Fig. 3. Relationship between overall ascending national IMR and the number of significant spatial clusters of sub-national IMR identified in the country, 2000 (or closest available year) (note: the trend line is estimated using a power function $[\mathrm{Y}=\mathrm{b} 0$ $*\left(\mathrm{X}^{\wedge} \mathrm{b} 1\right)$ OR $\left.\ln (\mathrm{Y})=\ln (\mathrm{b} 0)+(\mathrm{b} 1 * \ln (\mathrm{X}))\right]$ which fitted the observed data best). 
Table 1. Distribution of countries by our proposed three-part mortality indicator, 2000.

\begin{tabular}{|c|c|c|c|c|c|}
\hline $\begin{array}{l}\text { Mortality } \\
\text { A:B:Ci } \\
\text { strata }\end{array}$ & Countries (global IMR rank [descending]) & $\begin{array}{l}\text { Total } \\
\text { countries }\end{array}$ & $\begin{array}{l}\text { Total } \\
\text { population }\end{array}$ & $\begin{array}{l}\text { Total } \\
\text { births }\end{array}$ & $\begin{array}{l}\text { Mean IMR } \\
\text { [descending] } \\
\text { rank within strata }\end{array}$ \\
\hline $\mathrm{H}: \mathrm{L}: *$ & $\begin{array}{l}\text { Sierra Leone (1), Angola (2), Mali (5), Nigeria (6), Rwanda (10), } \\
\text { Somalia (11), Chad (13), Malawi (16), Burkina Faso (21), Benin } \\
\text { (23), Ethiopia (25), Uganda (27), Togo (30), Mauritania (31), } \\
\text { Pakistan (35), Haiti (37), Gambia (42) }\end{array}$ & 14 & $456,674,740$ & $17,970,880$ & 19.7 \\
\hline H:M:* & $\begin{array}{l}\text { Central African Republic (7), Liberia (8), Guinea (12), Burundi } \\
\text { (14), Sudan (14 } 4 \text {,45), Niger (18), Zambia (22), Cameroon (24), } \\
\text { Yemen (39), Senegal (42), Madagascar (43), Ghana (48), } \\
\text { Zimbabwe (50), Nepal (52) }\end{array}$ & 17 & $184,340,895$ & $7,113,530$ & 30.4 \\
\hline $\mathrm{H}: \mathrm{H}: *$ & $\begin{array}{l}\text { Democratic Republic of the Congo (3), Mozambique (4), Côte } \\
\text { d'Ivoire (19), Tanzania (31), Cambodia (34), Kenya (40), India } \\
\text { (47), Eritrea (49), Turkmenistan (58), South Africa (61), Botswana } \\
\text { (63) }\end{array}$ & 11 & $1,255,342,527$ & $35,019,142$ & 37.2 \\
\hline $\mathrm{H}: \mathrm{H}:$ & $\begin{array}{l}\text { Lesotho (29), Tajikistan (36), Comoros (38), Bangladesh (51), } \\
\text { Bolivia (57) }\end{array}$ & 5 & $149,449,225$ & $4,144,613$ & 42.2 \\
\hline $\mathrm{H}: \mathrm{H}:$ & $\begin{array}{l}\text { Afghanistan (19), Myanmar (53), Gabon (54), Papua New Guinea } \\
(60)\end{array}$ & 4 & $75,653,113$ & $2,270,986$ & 46.5 \\
\hline H:L: & $\begin{array}{l}\text { Swaziland (33), Congo, Rep. (41), Azerbaijan (59), Uzbekistan } \\
\text { (62) }\end{array}$ & 4 & $36,888,919$ & 798,610 & 48.8 \\
\hline M:H: & $\begin{array}{l}\text { Mongolia (65), Indonesia (74), Egypt (77), Iraq (81), Dominican } \\
\text { Republic (84), Nicaragua (82), Peru (88), Philippines (90), } \\
\text { Ecuador (97), Vietnam (100), Albania (104), Saudi Arabia (123) }\end{array}$ & 12 & $532,303,705$ & $12,678,436$ & 88.8 \\
\hline $\mathrm{M}: \mathrm{H}: *$ & Morocco (67), Brazil (85), China (92), Venezuela (116) & 4 & $1,490,267,574$ & $22,550,582$ & 90.0 \\
\hline M:M: & $\begin{array}{l}\text { Guyana (71), Algeria (72), Guatemala (75), Iran (78), Honduras } \\
\text { (92), Armenia (99), Mexico (102), Jordan (103), Bulgaria (121) }\end{array}$ & 9 & $235,731,593$ & $5,160,039$ & 90.3 \\
\hline M:L:" & Paraguay (91) & 1 & $5,350,253$ & 150,037 & 91.0 \\
\hline M:L: & $\begin{array}{l}\text { Kyrgyz Republic (70), Kazakhstan (76), Turkey (95), El Salvador } \\
\text { (98), Romania (105), Libya (107) }\end{array}$ & 6 & $116,534,459$ & $2,144,071$ & 91.8 \\
\hline M:M: & $\begin{array}{l}\text { Namibia (66), Tunisia (101), Colombia (109), Argentina (119), } \\
\text { Russian Federation (120) }\end{array}$ & 5 & $234,565,504$ & $3,101,064$ & 103.0 \\
\hline $\mathrm{L}: \mathrm{H}:$ & $\begin{array}{l}\text { Sri Lanka (125), Lebanon (127), Belarus (144), Greece (160), } \\
\text { Portugal (168), Australia (173), Sweden (190) }\end{array}$ & 7 & $81,510,807$ & $1,090,369$ & 155.3 \\
\hline $\mathrm{L}: \mathrm{M}: *$ & United States of America(159), Cuba (161), United Kingdom (165) & 3 & $352,193,341$ & $4,964,652$ & 161.7 \\
\hline L:L: & $\begin{array}{l}\text { Ukraine (128), Uruguay (132), Macedonia (134), Chile (152), } \\
\text { Poland (155), Croatia (157), Liechtenstein (171), Netherlands } \\
\text { (173), Switzerland (177), Denmark (180), Slovenia (182), Finland } \\
\text { (189), Japan (191) }\end{array}$ & 13 & $275,400,583$ & $2,760,894$ & 163.2 \\
\hline $\mathrm{L}: \mathrm{H}: *$ & Thailand (128), Canada (171), Italy (176), France (183) & 4 & $210,966,244$ & $2,593,012$ & 164.5 \\
\hline L:M: & $\begin{array}{l}\text { Costa Rica (142), Slovak Republic (149), Hungary (150), Czech } \\
\text { Republic (165), Spain (168), Austria (180), Germany (183), } \\
\text { Norway (188) }\end{array}$ & 8 & $164,778,858$ & $1,622,001$ & 165.6 \\
\hline L:L:* & New Zealand (163), Ireland (164), Iceland (192) & 3 & $7,944,079$ & 114,728 & 173.0 \\
\hline
\end{tabular}

i: A = mortality category (high[H], medium[M], low $[\mathrm{L}]$ ); B = mortality inequality level (high $[\mathrm{H}]$, medium[M], low $[\mathrm{L}])$; C = significant spatial autocorrelation present within country $(*=$ yes, blank $=$ no); ii: Source - http://data.worldbank.org/indicator/ for the year 2000; iii: Based on crude birth rate per 1,000 multiplied by the total population size; iv: South Sudan. 


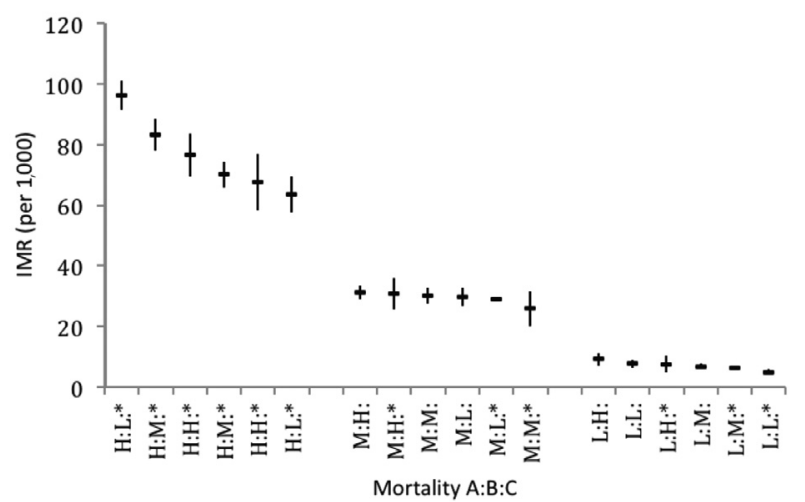

Fig. 4. Descending mean IMR (and $95 \%$ CI) by Mortality ${ }_{\mathrm{ABC}}$ strata.

by Mortality $\mathrm{ABC}$ strata and clearly shows that the worst apparent permutation is $\mathrm{H}: \mathrm{L}:$ " i.e. high mortality, low inequality and evidence of high risk spatial clustering (taking neighbouring contiguity (country) into account). Heterogeneity in mean IMR by strata decreases towards the low (L) IMR ("A" component of Mortality $\mathrm{ABC}_{\mathrm{ABC}}$ - see Fig. 4).

A global map of the Mortality ${ }_{A B C}$ Indicator, illustrated in Fig. $5^{1}$, shows the degree of mortality inequality in a colour format with the ranking system used in Table 1 superimposed on each country. Countries with higher mortality inequality are marked in darker shades. A dark shade over China, for instance, illustrates high mortality inequality $(\mathrm{H})$. China also recorded medium levels of absolute IMR and significant clusters

\footnotetext{
${ }^{1}$ Supplemental table (Appendix 4) contains all calculated country values for the 3 dimensions of the index including the raw metric values.
}

of high mortality that are centred on the map (M:H:*).

Greater inequality is observed outside of the developed region in general (Fig. 5) and the majority of SSA countries, for example, also fall into the high absolute mortality level category. Interestingly, greater inequality was observed in Asia compared to Africa and some clear distinctions across developing countries can be seen e.g. South Africa versus Brazil and China. Finally, Table 1 indicates that countries with higher levels of absolute mortality tend to also have significant levels of spatial clustering present (as observed by the aggregation of counts in these rows). We do not, however, observe this pattern in countries with medium and low absolute mortality levels categories in which we see a reversal in this trend, i.e. more countries aggregated in the non-spatial clustering rows (Fig. 3).

\section{Discussion}

This paper proposes that the novel, three-part, mortality indicator (Mortality ${ }_{\mathrm{ABC}}$ ) could be used as a first step to identify and spatially allocate healthcare resources for both national and global policy makers. The paper has used relative mortality inequality to illustrate the distribution of IMR and it does not conflate health inequality with health inequity which we have assumed is only considered when developing the detail of an intervention taking into account specific country level data (Reidpath, 2005; Reidpath and Allotey, 2007). The empirical example (and choice of IMR) of our three-part indicator was primarily employed to illustrate its potential appeal rather than argue its appropriateness as the ideal indicator of population health. Future applications should test and utilise age standardised, gender-specific all-cause mortality to fur-

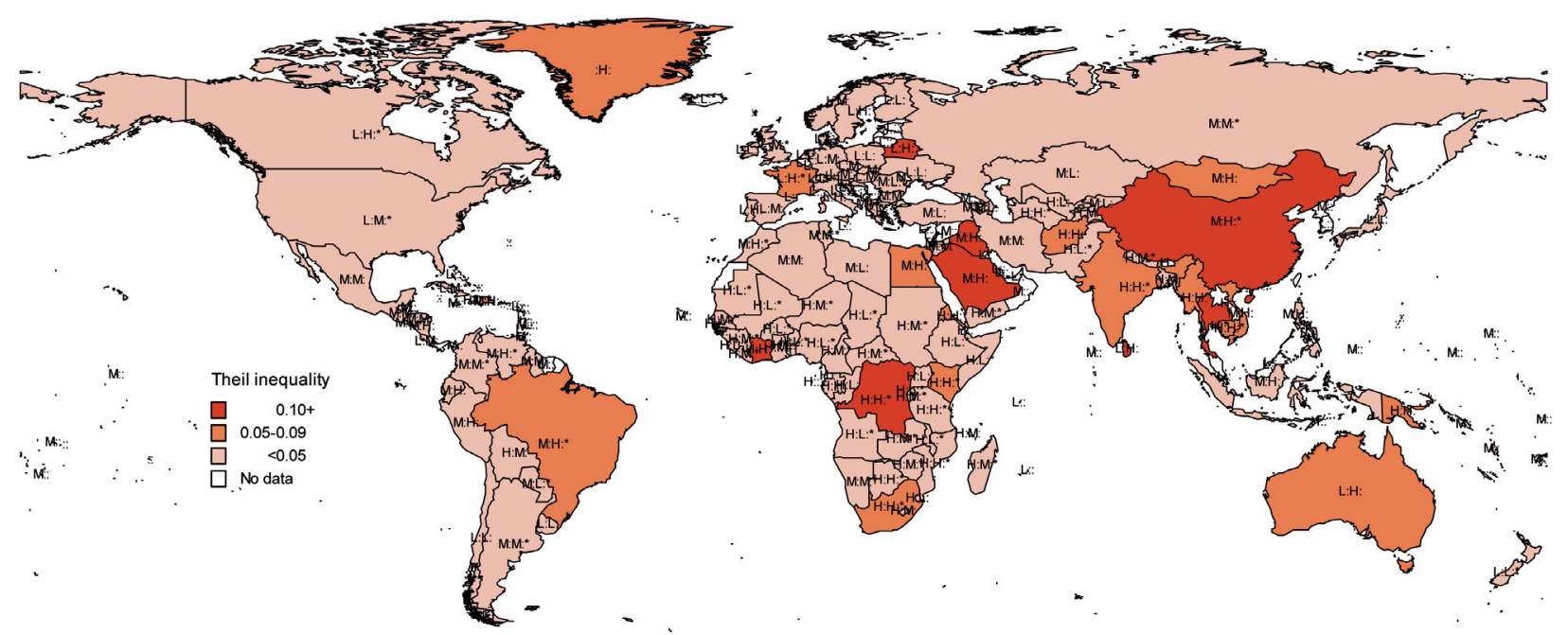

Fig. 5. Global map displaying IMR inequality and our proposed three-part mortality indicator, 2000 (or closest available year). 
ther assess the utility of the multi-attribute indicator and deciding as to its potential re-use by policy makers.

Life expectancy in certain high-income countries has increased in the last 30 years while the impact of HIV/AIDS is clearly evident in SSA where we observed the highest levels of IMR (Lewis, 2006; Watkins et al., 2006). The classification of countries in the various permutations of the Mortality ${ }_{\mathrm{ABC}}$ (Table 1) highlights that countries within various IMR absolute level categories are very much different in terms of inequality and spatial clustering. The explanation of these differences, however, is not explained by the proposed index but by differences in country-level social determinants that include education, service delivery, economic (e.g. GDP), social/cultural and institutional (Reidpath and Allotey, 2007; Marmot et al., 2012; Sartorius and Sartorius, 2013b). The proposed index merely spatially locates IMR problems in this region and it is assumed policy makers would then be guided by both inequality and inequity issues when differentiating the degree and type of intervention required (Lewis, 2006; Sartorius and Sartorius, 2013a). Marmot et al. (2012) proposes that one-dimensional interventions are not the answer but rather multifaceted type interventions. We propose that our measure has definite implications for policy and affects potential policy-related strategy i.e. choice of broad population level type interventions versus target interventions to high risk areas (spatial concentration) within a given country. Marmot suggests four key ways in which inequalities can potentially be tackled: control of major diseases, the improvement health systems, the reduction of poverty and tackling social determinants of health.

Global policies that allocate aggregated funding to countries, moreover, have continued to be guided by the overall country-level mortality but there is a need for a multi-attribute index that clearly identifies spatial health inequalities within a country when deciding on intervention strategies-budget allocation. A measure of population health must also take into account the distribution of health within that population (Sen, 1999; Dreze and Sen, 2002). Component A would drive budget size for example (absolute level x population size) while components $\mathrm{B}$ and $\mathrm{C}$ (both essentially point to inequality) drive where the budget is best administratively directed i.e. policy guidance measures. Therefore the three attributes cannot be collapsed in terms of importance (i.e. converted into a single value) but rather allows countries to be placed within strata (based on permutations of the components) which can then best assist policy guidance (when combined with potential population at risk in that strata). We provide some example decision making rules below that could potentially accompany our multiattribute indicator and assist broad policy making strategies (Table 2). Thus our index does not only identify countries with high IMR, i.e. high burden (which is not novel), but also assesses the intra-country distribution of a given phenomenon, i.e. equity. The Theil index is a measure of inequality or volatility that involves similar properties to measures of mean and standard deviation as proposed when evaluating two populations (Reidpath, 2005). Our multi-attribute measure goes one step further in that it then also identifies the exact spatial location of inequality and significant spatial clustering of high values i.e. spatial identification of higher levels of inequality within subnational units of a country. The use of the Mortality ${ }_{A B C}$ measure, therefore, is rather to spatially locate and quantify (and/or highlight and/or differentiate) high risk areas in order to prompt differential levels of investigation as well as the intra-country allocation of funds. Possibly the biggest benefit of the index is when it is decomposed to show intra-country differences, it would guide relative budget allocation within a country rather than homogeneously dilute budget allocations over a whole country. It does this by showing that in certain countries a standard IMR policy is not appropriate where sub-national localities are unequal and/or where high levels of clustering are potentially present. In this scenario, the first budget allocations should be made to areas of inequality and/or spatial clustering. The paper focuses primarily in health inequality as the first step for drawing attention for the need for a differential intervention. The index can, therefore, be employed to tailor an intervention in a far more acute fashion, i.e. countries in strata with high inequality and/or containing significant high risk subnational units should first adopt a targeted ("focused") strategy to reduce mortality in these areas before adopting or modifying more national based strategies. The magnitude and extent of the intervention is then based on specific social determinants in a specific country (or region) accounting for differential levels of inequity (Kawachi and Wamala, 2007), which is not ignored in this paper but seen as a later step when investigating the specific determinants of the problem. There is also the assumption that each country will have or collect additional data with regards to genderdeterminants when developing local and national policy. The usefulness of a spatial measure of health inequality is that budgets allocations are largely develo- 
Table 2. Some example decision making rules based on the permutations of the Mortality ${ }_{\mathrm{ABC}}$ indicator.

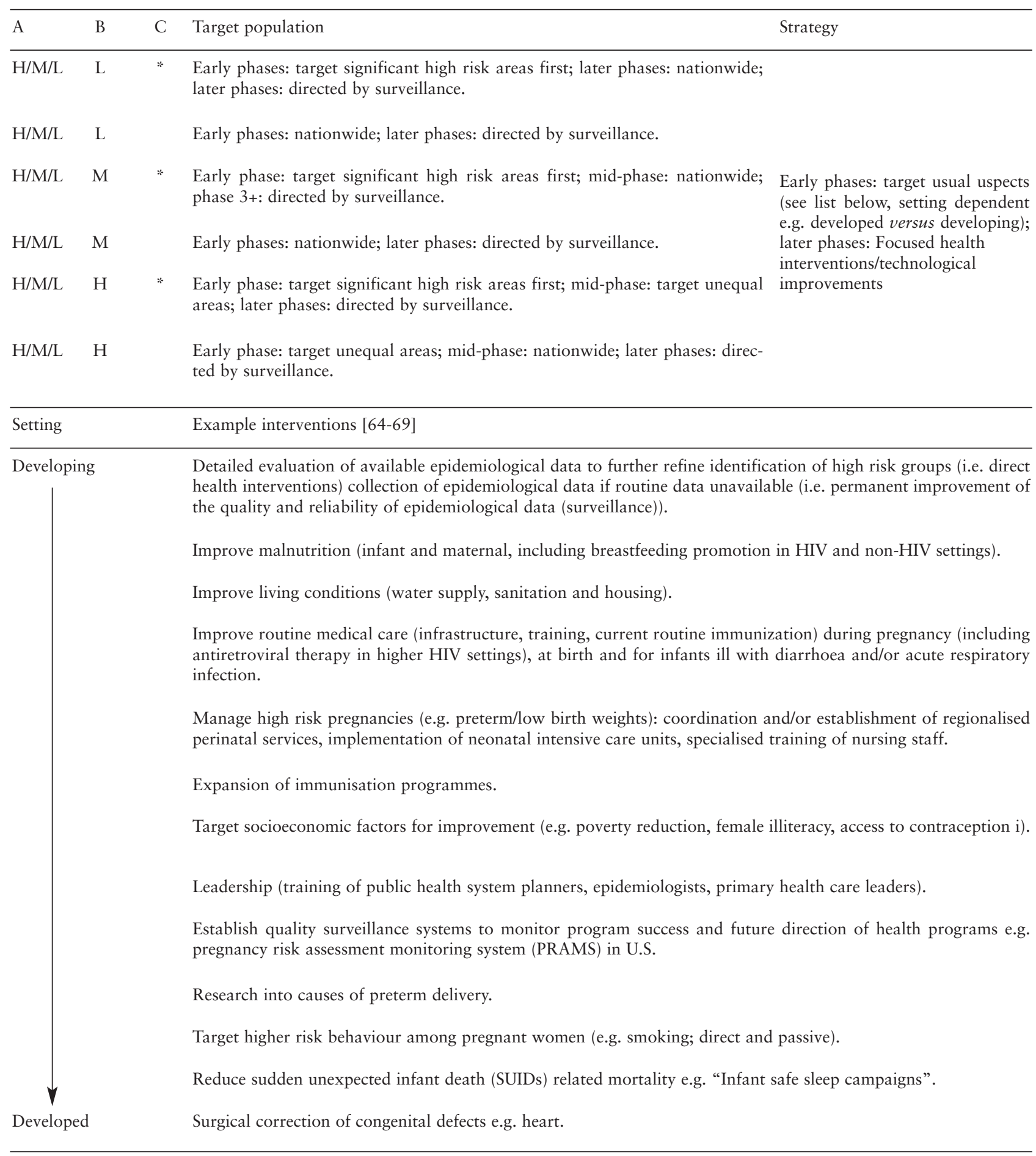

ped on a region/country/area basis for administration purposes.

The Mortality ABC $_{\mathrm{A}}$ indicator can also be developed for intra-country policy interventions. The indicator can, therefore, be easily adapted to lower administrative areas like provinces, local municipalities (as Theil is suitable for decomposition) as well as for other health outcomes measures. The paper also directs specific attention to the newly revived inequality debate in support of the contention that inequality is increasing rather than converging in many (Rajaratnam et al., 2010). In particular, the paper questions the use of absolute mortality rates as a self-limiting one-dimensional approach that obscures the type of policy that 
needs to be developed, as well as narrows its application to a limited segment of the population or dilutes interventions over an entire population (instead of targeting them to the worst areas), rendering them less effective (Murray et al., 2000).

The results illustrate that the reliability of the framework is supported by a number of other studies that reflect higher mortality levels in developing areas like SSA and lower levels in the developed world (Mathers et al., 2006). However, no other studies present a global snapshot of sub-national variation that is reflected in high levels of mortality inequality in both developed and developing countries (Wolfson and Rowe, 2001). This inequality reflects the inadequacy of absolute health measures like the IMR to inform a differentiated intra-country policy (Gakidou et al., 2000). The intra-country complexity of mortality data is illustrated by the United States where absolute mortality has consistently declined in the last century yet higher levels of mortality continue to be reflected in its 20 southern states (Peltzman, 2009). This nuanced pattern of inequality, as well as its spatial location, therefore, calls for a multidimensional indicator that not only highlights inequality but also significant spatial clustering ("non-randomness").

The paper contributes to the inequality debate by illustrating the widespread nature of mortality inequality and its changing patterns. The convergence of global mortality until the 1950 s, for example, has been contradicted by increasing mortality in many developing countries (McMichael et al., 2004) whose healthcare budgets differ significantly from those of richer countries. Inter-country changes in inequality are also illustrated in the developed world where the USA and Australia, for example, had lower levels of inequality than Spain and Japan in 1900 but higher levels in 2000 (Peltzman, 2009). These disparities are likely to continue to be shaped by stratified access to and utilisation of medical technology (Frisbie et al., 2004) and these intra-country changes reflect a greater divergence between the healthcare access of the rich and the poor (Deaton, 2013). We found very high inequality in China based on our analysis. China has undergone large social, economic and political changes in recent decades and underlying geographic differences in economic status and maternal education (Song and Burgard, 2011) for example are likely to explain this observed differential pattern. It is also not surprisingly that countries such as Iraq and the Democratic Republic of the Congo have high inequality given past political instability, war and resulting in material deprivation, breakdown in basic services and healthca- re provision as well as dysfunctional societies within the country (Marmot, 2005).

The use of spatial analysis has been increasingly applied in epidemiological research in recent years and advances in data availability and new analytic methods now allow for the spatial analysis of population health data from global to local level (Walter, 2000; Rezaeian et al., 2007). In particular, these spatial analytical techniques can be used to identify "hotspots" in population health distributions and show the clustering of health phenomena in a country or region, as well as describe their spatial patterns (Sartorius et al., 2011). This has implications for policy in terms of whether a spatially tailored approach is adopted versus a more disseminated one (Sartorius and Sartorius, 2013a). The results make a case, therefore, for the use of simple inferential spatial statistics (implemented in freely available software such as GeoDa) as a component of a multidimensional population health indicator.

The paper has a number of limitations. Firstly, country-level data with a greater number of sub-groups for the same absolute population level is likely to reflect a higher level of mortality inequality because the standard deviation across sub-groups increases. However, based on a simple comparison of the vulnerability of the inequality calculated versus the number of subnational units we observed that the Theil index was less affected then the widely used Gini coefficient. As data for certain sub-national areas within selected countries could not be found (Storeygard et al., 2008), this resulted in data for fewer sub-national units within a given country and potentially underestimated inequality. Secondly, population groups are only comparable if they have a similar population density (Wolfson and Rowe, 2001), which is clearly that the case globally. Thirdly, we were unable to find subnational mortality rates for some countries due to a lack of available data. The variable quality of data by country can also not be discounted (e.g. data points further away from the year 2000) and future work could also concentrate on data development and quality to ensure more consistent sub-national data. Fourthly, survey data are subject to various sources of bias and error and these are generally well documented for infant and child mortality (Hobcraft et al., 1984) e.g. non-response, sampling bias etc. While vital statistics are ideal if there is good coverage, if the system is weak, deaths can be greatly under-reported both nationally and in selected sub-national units (Storeygard et al., 2008). Further details of the quality of the original data and inferences made can be found in Storeygard et al (Storeygard et al., 2008). Fifthly, 
the data source used in this study were not stratified (i.e. available) by gender, which is a fundamental determinant of infant (and other) mortality (Barford et al., 2006). This should be considered as a further stratification of the multi-attribute dimension in future studies. We have assumed that this level of data would be sought only when developing intra-country interventions using specific data for the country concerned. The inclusion of gender, however, in future research on the development of multidimensional health indicators is suggested Lastly, previous literature (Cowell and Flachaire, 2007) has suggested that inequality measures are in general sensitive to extreme values (due to war, famine and natural catastrophes) or "data contamination". Thus data quality would affect the analysis in our present study as outlying or erroneous subnational IMR's may thus have affected the calculated Theil measures. Future studies will need to further assess the sensitivity ("robustness") of this and other inequality measures to data distortions, especially in different parts of the distribution as this has been shown to be potentially important (Cowell and Victoria-Feser, 1996).

\section{Acknowledgements}

We thank CIESIN for freely providing the empirical data used to demonstrate our proposed indicator.

\section{References}

Allison PD, 1978. Measures of inequality. Am Sociol Rev 43, 865-880.

Anselin L, 1996. Local indicators of spatial association - LISA. Geogr Anal 27, 93-115.

Anselin L, Ibnu S, Youngihn K, 2006. GeoDa: an introduction to spatial data analysis. Geogr Anal 38, 5-22.

Anselmi L, Fernandes QF, Hanson K, Lagarde M, 2013. Accounting for geographical inequalities in the assessment of equity in health care: a benefit incidence analysis. Lancet 381 , S9.

Atkinson AB, 1970. On the measurement of inequality. J Econ Theory 2, 244-263.

Barford A, Dorling D, Smith GD, Shaw M, 2006. Life expectancy: women now on top everywhere: during 2006, even in the poorest countries, women can expect to outlive men. BMJ 332, 808 .

Bessudnov A, McKee M, Stuckler D, 2012. Inequalities in male mortality by occupational class, perceived status and education in Russia, 1994-2006. Eur J Public Health 22, 332-337.

CIESIN, 2005. Center for International Earth Science Information Network (CIESIN)/Columbia University. Poverty mapping project: global sub-national infant mortality rates. Palisades, NY: NASA Socioeconomic Data and Applications Center (SEDAC). Available at: http://sedac.ciesin.columbia. edu/data/set/povmap-global-subnational-infant-mortalityrates (accessed on August 2012).

Cowell FA, Flachaire E, 2007. Income distribution and inequality measurement: the problem of extreme values. J Econometrics 141, 1044-1072.

Cowell FA, Victoria-Feser M-P, 1996. Robustness properties of inequality measures. Econometrica, 77-101.

Coyne JS, Hilsenrath P, 2002. The world health report 2000: can health care systems be compared using a single measure of performance? Am J Public Health 92, 30-33.

Deaton A, 2001. Relative deprivation, inequality, and mortality. National Bureau of Economic Research.

Deaton A, 2013. What's wrong with inequality? Lancet 381, 363.

Dreze J, Sen AK, 2002. India: development and participation. Oxford: Oxford University Press.

Ezzati M, Lopez A, Rodgers A, Vander Hoorn S, Murray C, Comparative Risk Assessment Collaborating Group, 2002. Selected major risk factors and global and regional burden of disease. Lancet 360, 1347-1360.

Firebaugh G, 1999. Empirics of world income inequality 1. Am J Sociology 104, 1597-1630.

Frisbie WP, Song S-E, Powers DA, Street JA, 2004. The increasing racial disparity in infant mortality: respiratory distress syndrome and other causes. Demography 41, 773-800.

Gakidou EE, Murray CJL, Frenk J, 2000. Defining and measuring health inequality: an approach based on the distribution of health expectancy. Bull World Health Organ 78, 42-54.

Getis A, Ord J, 1992. The analysis of spatial association using distance statistics. Geogr Anal 24, 189-206.

Getis A, Ord J, 1995. Local spatial autocorrelation statistics: distributional issues and an application. Geogr Anal 27, 287306.

Goldthorpe JH, 2010. Analysing social inequality: a critique of two recent contributions from economics and epidemiology. Eur Sociol Rev 26, 731-744.

Greenland S, 2005. Epidemiologic measures and policy formulation: lessons from potential outcomes. Emerg Themes Epidemiol 2, 5 .

Hale T, 2003. The theoretical basics of popular inequality measures. Online computation of examples. University of Texas inequality project.

Hobcraft JN, McDonald JW, Rutstein SO, 1984. Socio-economic factors in infant and child mortality: a cross-national comparison. Popul Stud 38, 193-223.

Houweling TAJ, Kunst AE, Looman WN, Mackenbach P, 2005. Determinants of under- 5 mortality among the poor and rich: a cross analysis of 43 developing countries. Int J Epidemiol 24, 1257-1265. 
Houweling TAJ, Kunst AE, Mackenbach JP, 2001. World health report 2000: inequality index and socioeconomic inequalities in mortality. Lancet 357, 1671-1672.

Hughes BB, Kuhn R, Peterson CM, Rothman DS, Solórzano JR, Mathers CD, Dickson JR, 2011. Projections of global health outcomes from 2005 to 2060 using the international futures integrated forecasting model. Bull World Health Organ 89, 478-486.

Jenkins S, 1999. Stata module to calculate inequality indices with decomposition by subgroup. S366002nd edition. Boston: Boston College, Department of Economics.

Kawachi I, Wamala SP, 2007. Globalization and health. Oxford: Oxford University Press.

Lewis S, 2006. Race against time: searching for hope in AIDSravaged Africa: House of Anansi.

Mackenbach JP, Kunst AE, Cavelaars AEJM, Groenhof F, Geurts JJM, 1997. Socioeconomic inequalities in morbidity and mortality in western Europe. Lancet 349, 1655-1659.

MapInfo Corporation, 2008. MapInfo professional: version 9.5. Stamford, USA: Pitney Bowes Software.

Marmot M, 2005. Social determinants of health inequalities. Lancet 365, 1099-1104.

Marmot M, Allen J, Bell R, Goldblatt P, 2012. Building of the global movement for health equity: from Santiago to Rio and beyond. Lancet 379, 181-188.

Mathers C, Lopez A, Murray C, 2006. The burden of disease and mortality by condition: data, methods and results for 2001. In: Global burden of disease and risk factors. Lopez AD, Mathers CD, Ezzati M, Jamison D, Murray CJL (eds). New York: Oxford University Press, 45-240 pp.

McMichael AJ, McKee M, Shkolnikov V, Valkonen T, 2004. Mortality trends and setbacks: global convergence or divergence? Lancet 363, 1155-1159.

Milanovic B, 2002. True world income distribution, 1988 and 1993: first calculation based on household surveys alone. Econ J 112, 51-92.

Murphy M, Bobak M, Nicholson A, Rose R, Marmot M, 2006. The widening gap in mortality by educational level in the Russian Federation, 1980-2001. Am J Public Health 96, 12931299.

Murray C, 1996. Rethinking DALYs. The global burden of disease: a comprehensive assessment of mortality and disability from diseases, injuries, and risk factors in 1990 and projected to 2020. Cambridge: Harvard School of Public Health, 1$98 \mathrm{pp}$.

Murray CJ, Lopez AD, 1997. Alternative projections of mortality and disability by cause 1990-2020: global burden of disease study. Lancet 349, 1498-1504.

Murray CJ, Salomon JA, Mathers C, 2000. A critical examination of summary measures of population health. Bull World Health Organ 78, 981-994.

Murray CJ, Lopez AD, 1997. Alternative projections of morta- lity and disability by cause 1990-2020: Global Burden of Disease Study. Lancet 349 (9064), 1498-1504.

Obermeyer Z, Rajaratnam JK, Park CH, Gakidou E, Hogan MC, Lopez AD, Murray CJL, 2010. Measuring adult mortality using sibling survival: a new analytical method and new results for 44 countries, 1974-2006. PLoS Med 7, e1000260.

Pedersen A, 2004. Inequality as relative deprivation: a sociological approach to inequality measurement. Acta Sociol 47, 31-49.

Peltzman S, 2009. Mortality inequality. J Econ Perspect 23, 175 190.

Rajaratnam JK, Marcus JR, Levin-Rector A, Chalupka AN, Wang H, Dwyer L, Costa M, Lopez AD, Murray CJL, 2010. Worldwide mortality in men and women aged 15-59 years from 1970 to 2010: a systematic analysis. Lancet 375, 17041720.

Reidpath DD, 2005. Population health. More than the sum of the parts? J Epidemiol Community Health 59, 877-880.

Reidpath DD, Allotey P, 2003. Infant mortality rate as an indicator of population health. J Epidemiol Community Health 57, 344-346.

Reidpath DD, Allotey P, 2007. International Journal for Equity in Health. Int J Equity Health 6, 16.

Rezaeian M, Dunn G, St Leger S, Appleby L, 2007. Geographical epidemiology, spatial analysis and geographical information systems: a multidisciplinary glossary. J Epidemiol Community Health 61, 98-102.

Sartorius B, Sartorius K, 2013a. Identifying and targeting mortality disparities: a framework for Sub-Saharan Africa using adult mortality data from South Africa. PLoS One 8, e71437. Sartorius B, Sartorius K, Chirwa TF, Fonn S, 2011. Infant mortality in South Africa-distribution, associations and policy implications, 2007: an ecological spatial analysis. Int J Health Geogr 10, 61.

Sartorius K, Sartorius BK, 2013b. A spatial model to quantify the mortality impact of service delivery in Sub-Saharan Africa: an ecological design utilizing data from South Africa. Int J Health Geogr 12, 8.

Sen A, 1999. Development as freedom. Oxford: Oxford University Press.

Shorrocks AF, 1980. The class of additively decomposable inequality measures. Econometrica 613-625.

Song S, Burgard SA, 2011. Dynamics of inequality: mother's education and infant mortality in China, 1970-2001. J Health Soc Behav 52, 349-364.

StataCorp, 2013. Stata statistical software: release 13. College Station, TX: StataCorp LP (release).

Stiglitz JE, 2012. The Price of inequality: how today's divided society endangers our future: WW Norton.

Storeygard A, Balk D, Levy M, Deane G, 2008. The global distribution of infant mortality: a subnational spatial view. Popul Space Place 14, 209-229.

UNICEF, 2004. End-decade database on child mortality. 
Available at: www.childinfo.org (accessed on ... 2004).

Walter S, 2000. Disease mapping: a historical perspective. Spatial Epidemiology - Methods and Applications. Oxford: Oxford University Press.

Watkins K, Carvajal L, Coppard D, Fuentes R, Ghosh A, Giamberardini C, Johansson C, Seck P, Ugaz C, Yaqub S, 2006. Human development report 2006. Beyond scarcity: power, poverty and the global water crisis. New York: United Nations Development Programme (UNDP).
Wilkinson R, Pickett K, 2006. Income inequality and population health: a review and explanation of the evidence. Soc Sci Med 62, 1768-1784.

Wilkinson RG, 1992. National mortality rates: the impact of inequality? Am J Public Health 82, 1082-1084.

Wolfson M, Rowe G, 2001. On measuring inequalities in health. Bull World Health Organ 79, 553-560.

Yitzhaki S, 1979. Relative deprivation and the Gini coefficient. Q J Econ 93, 321-324. 


\section{Appendix 1: Supplemented IMR data}

Supplemental data were found for the following The year which the supplemented data were availacountries (ISO 3 codes): AFG, AUS, AUT, BEL, BGR, ble is listed below (mostly from 2000-2002). The BRA, CHE, CHN, CIV, COG, CZE, DEU, DNK, ESP, count exceeds the 43 countries above as for 5 countries FIN, FRA, GBR, GRC, HRV, HUN, IRL, IRQ, ITA, data from more than one year was used in our analysis JPN, KAZ, KGZ, LBR, LBY, MKD, NLD, NOR, POL, in an attempt to include data for as many subnational PRT, ROU, SAU, SLE, SVK, SVN, SWE, TCD, TJK, units as possible.

UKR, ZAR.

\begin{tabular}{|c|c|}
\hline Year/period & Frequency \\
\hline 1987 & 1 \\
\hline 1990 & 1 \\
\hline 1990-2000 & 1 \\
\hline 1991-2003 & 1 \\
\hline 1992 & 2 \\
\hline 1996 & 1 \\
\hline 1996-1997 & 1 \\
\hline 1996-2005 & 1 \\
\hline 1997 & 2 \\
\hline 1998 & 1 \\
\hline 1999 & 1 \\
\hline 2000 & 4 \\
\hline 2001 & 22 \\
\hline 2002 & 5 \\
\hline 2003 & 1 \\
\hline 2004 & 1 \\
\hline 2005 & 1 \\
\hline 2007 & 1 \\
\hline 2008 & 1 \\
\hline Total & 49 \\
\hline
\end{tabular}




\section{Appendix 2 - Selection of the most appropriate inequality measure for mortality}

The following is the checklist we used for selecting the inequality index for our proposed three-part indicator:

\section{a. Scale invariance}

Two populations with the same level of mortality inequality may have very different average mortality levels. The question, therefore, should be posed as to whether a relative versus an absolute measure of inequality should be employed (Gakidou et al., 2000).It is preferable that inequality measures respond to relative rather than absolute differences (Allison, 1978). All of the inequality variances discussed in the methods (and in Appendix 2) are relative measures of inequality and inequality in all of them is reduced if a positive constant is added to each member of the population being measured.

\section{b. Principle of transfers}

The chosen measure must comply with the principle of transfers that indicates that if a greater degree of life expectancy (e.g. lower infant mortality risk) is transferred from an individual with a lower life expectancy to another with a higher level of life expectancy, the degree of mortality inequality will increase (Allison, 1978). One of the measures fails this principle, namely, the VOL and is, therefore, excluded immediately.

\section{c. Sensitivity of transfers}

The remaining measures, namely, the COV, Gini and Theil indexes, indicate different levels of sensitivity to transfers at different parts of their welfare distributions and the question needs to be asked whether gains or losses at the tails of a distribution should be treated differently from those at the mean (Gakidou et al., 2000). For example, the Gini is more affected by transfers at the mid-range while the Theil is more influenced by transfers at lower levels. Conversely, the $\mathrm{COV}$ is equally sensitive to transfers at all levels of the distribution. Allison, therefore, concludes that the choice of the Gini might be appropriate if one is mostly concerned about the middle range of a welfare distribution (Allison, 1978). However, given the sociological and ethical nature of maximizing life expectancy (reducing preventable health outcomes), and its unequal effect on more deprived communities, the sensiti- vity of the Theil index at lower ranges is an important sociological consideration for favouring the use of this index (Pedersen, 2004).

\section{d. Upper and lower bounds}

The remaining inequality measures, namely, the COV, Gini and Theil, can all be structured to have a lower and upper bound that ranges between zero (0) and one (1) where these bounds reflect the distance from a state of equality. Theil argues that in a society where everyone had the same life expectancy or rate of health outcome there would be perfect equality (0) whilst in a two person society for example where one person lived to the maximum age and the second died at birth (or infancy) can be represented a state of complete inequality (1).

\section{e. Inequality, interval scales and the Lorenz curve}

Since certain health outcomes have a theoretical fixed point of zero, it can be seen as a ratio scale variable that is suited to the three remaining inequality measures, namely, the Gini, Theil or COV indicators, Furthermore, the remaining three measures have a simple relationship with the Lorentz curve as follows. They each represent a cumulative relationship between two variables, namely, the proportion of a population and the level of a welfare utility (Atkinson, 1970). Any distribution that is not in a state of perfect equality will fall below the line of perfect equality. If the Lorenz curves of two distributions are compared then the distribution with the lower level of welfare will always fall below the distribution with the higher level of welfare or lower inequality (Atkinson, 1970; Allison, 1978).

\section{f. Decomposition}

An important aspect of consideration is whether the inequality measure can be decomposed to measure inequality within groups, as well as between groups. In the USA, for instance, it is important to obtain a measure of mortality inequality within the various states, as well as between the states. Despite the fact that the Gini Coefficient is the most popular measure, as well as the fact that it has been used to calculate mortality inequality (Peltzman, 2009), it is not decomposable. Conversely, both the COV and the Theil index are additive and can decomposed to calculate within 
groups inequality, as well as between groups inequality (Atkinson, 1970).

\section{g. Conclusion}

In terms of selecting an inequality measure the $\mathrm{VOL}$ was dropped because it did not comply with the principle of transfers and the Gini because it is not (easily) decomposable into sub-groups. The Theil and COV measures adhere to the principal of transfers, are scale invariant, they can be plotted as a Lorenz curve and their upper and lower range can be appealingly related to one (1) and zero (0). However, the Theil is best sui- ted to measuring a utility with diminishing returns or marginal utility (e.g. income) while the COV is the best choice for measuring a utility with constant returns. On the assumption that increasing lifespan is offset with increased morbidity, decreasing returns have been assumed thus favouring the choice of the more popular Theil index that is particularly suited to measuring inequality in a population disaggregated into a set of sub-groups (Shorrocks, 1980). Finally, the Theil index might reflect less inequality in developing countries and higher inequality in developed ones because of differences in their welfare distributions (Allison, 1978). 
Appendix 3 - Other inequality indices and construction of the Theil inequality index

Inequality can be conceptualised as the dispersion of a distribution such as income, or some other welfare indicator or attribute of a population. A general expression for a mortality inequality index (I) for group $\mathrm{j}=1 \ldots . . \mathrm{J}$ is defined earlier in the methods as follows (Firebaugh, 1999):

$$
I=\sum_{j} p_{j} f\left(r_{j}\right)
$$

The three other principle variances mentioned in the methods (namely the COV, the Gini Coefficient, and the VOL) differ only because they employ different functions (f) of the chosen social welfare distribution illustrated as follows:

$$
\begin{gathered}
\operatorname{COV}_{j}=f\left(r_{j}\right)=\left(r_{j}-1\right)^{2} \\
\operatorname{Gini}_{j}=f\left(r_{j}\right)=r_{j}\left(q_{j}-Q_{j}\right)
\end{gathered}
$$

where $\mathrm{q}_{\mathrm{j}}$ is the proportion of population that has a worse IMR than unit $j$ and $Q_{j}$ the proportion that are better IMR than group $j$.

$$
\operatorname{VOL}_{i}=f\left(r_{i}\right)=\left[\log \left(r_{i}\right)-E\left[\log \left(r_{i}\right)\right]\right]^{2}
$$

where $\mathrm{E}$ is the expected value, log is the natural logarithm.

The Theil index $\left(T_{j}\right)$ can be represented mathematically as follows:

$$
T_{j}=\mathrm{f}\left(\mathrm{r}_{\mathrm{j}}\right)=\mathrm{r}_{\mathrm{j}}\left(\log \mathrm{r}_{\mathrm{j}}\right)
$$

(equation 1)

\section{The Theil index}

The Theil index can be described as a measure of entropy or randomness in a given set of information across different groups or administrative divisions. Equation (1) can be restated as follows:

$$
T_{j}=\sum_{i=1}^{n}\left(\frac{x_{i}}{N \bar{x}}\right)\left(\frac{1 \mathrm{n} N \bar{x}}{x_{j}}\right)
$$

(equation 2)

The Theil index $(\mathrm{T})$ is and can be decomposed as follows:

Suppose a social welfare distribution (population) can be divided into J exclusive and exhaustive groups. For each group $\mathrm{j}=1 \ldots \mathrm{J}$ let $\bar{x}_{j}$ be the mean outcome measure in group $j$ and the proportion of the population represented by this group $\mathrm{p}_{\mathrm{j}}$. Let $\bar{x}=$ the total mean outcome measure then:

$$
T=\sum_{i=1}^{J}\left(\frac{p_{i} \bar{x}_{j}}{\bar{x}}\right)\left(\frac{\log \bar{x}_{i}}{\bar{x}}\right)+\sum_{j=1}^{J}\left(\frac{p_{j} \bar{x}_{j}}{\bar{x}}\right)
$$

(equation 3)

where $p_{j}=$ proportion of group $j$ to the population $P$. The additive sum of inequality within countries, as well between countries is similar to the ANOVA based calculation:

$$
\frac{\sum_{i} \sum_{i}\left(x_{i j}-\bar{x}\right)^{2}}{N}=\left(\frac{\sum n_{j}\left(x_{i j}-\bar{x}_{j}\right)^{2}}{N}\right)+\left(\frac{\sum_{j} \sum_{i} n_{j}\left(x_{i j}-\bar{x}_{j}\right)^{2}}{N}\right)
$$

(equation 4) 
Appendix 4 - Country values for the 3 dimensions of the index including the raw metric values

\begin{tabular}{|c|c|c|c|c|c|c|c|c|}
\hline Sierra Leone & 145.5 & 1 & $\mathrm{H}$ & 0.004 & 115 & $\mathrm{~L}$ & 1 & $\mathrm{HL}^{*}$ \\
\hline Angola & 118.7 & 2 & $\mathrm{H}$ & 0.008 & 107 & $\mathrm{~L}$ & 6 & $\mathrm{HL}^{*}$ \\
\hline Democratic Republic of the Congo & 117.3 & 3 & $\mathrm{H}$ & 0.203 & 3 & $\mathrm{H}$ & 1 & $\mathrm{HH}^{*}$ \\
\hline Mozambique & 116 & 4 & $\mathrm{H}$ & 0.040 & 36 & $\mathrm{H}$ & 10 & $\mathrm{HH}^{*}$ \\
\hline Mali & 113.9 & 5 & $\mathrm{H}$ & 0.007 & 109 & $\mathrm{~L}$ & 6 & $\mathrm{HL}^{*}$ \\
\hline Nigeria & 112.5 & 6 & $\mathrm{H}$ & 0.014 & 92 & $\mathrm{~L}$ & 5 & $\mathrm{HL}^{*}$ \\
\hline Central African Republic & 112.3 & 7 & $\mathrm{H}$ & 0.024 & 67 & M & 6 & $\mathrm{HM}^{*}$ \\
\hline Liberia & 112 & 8 & $\mathrm{H}$ & 0.037 & 44 & M & 1 & $\mathrm{HM}^{*}$ \\
\hline Rwanda & 108.8 & 10 & $\mathrm{H}$ & 0.014 & 89 & $\mathrm{~L}$ & 12 & $\mathrm{HL}^{*}$ \\
\hline Somalia & 108.3 & 11 & $\mathrm{H}$ & 0.003 & 117 & $\mathrm{~L}$ & 1 & $\mathrm{HL}^{*}$ \\
\hline Guinea & 105.3 & 12 & $\mathrm{H}$ & 0.020 & 74 & M & 5 & $\mathrm{HM}^{*}$ \\
\hline Chad & 105 & 13 & $\mathrm{H}$ & 0.007 & 108 & $\mathrm{~L}$ & 1 & $\mathrm{HL}^{*}$ \\
\hline Burundi & 100.1 & 14 & $\mathrm{H}$ & 0.035 & 45 & M & 1 & $\mathrm{HM}^{*}$ \\
\hline Malawi & 98.4 & 16 & $\mathrm{H}$ & 0.008 & 106 & $\mathrm{~L}$ & 3 & $\mathrm{HL}^{*}$ \\
\hline Niger & 97 & 18 & $\mathrm{H}$ & 0.016 & 84 & M & 5 & $\mathrm{HM}^{*}$ \\
\hline Afghanistan & 94.9 & 19 & $\mathrm{H}$ & 0.074 & 13 & $\mathrm{H}$ & 0 & $\mathrm{HH}$ \\
\hline Côte d'Ivoire & 94.9 & 19 & $\mathrm{H}$ & 0.132 & 6 & $\mathrm{H}$ & 1 & $\mathrm{HH}^{*}$ \\
\hline Burkina Faso & 94.6 & 21 & $\mathrm{H}$ & 0.001 & 125 & $\mathrm{~L}$ & 4 & $\mathrm{HL}^{*}$ \\
\hline Zambia & 91 & 22 & $\mathrm{H}$ & 0.032 & 52 & M & 7 & $\mathrm{HM}^{*}$ \\
\hline Benin & 86.6 & 23 & $\mathrm{H}$ & 0.014 & 90 & $\mathrm{~L}$ & 6 & $\mathrm{HL}^{*}$ \\
\hline Cameroon & 86.3 & 24 & $\mathrm{H}$ & 0.037 & 43 & M & 4 & $\mathrm{HM}^{*}$ \\
\hline Ethiopia & 86 & 25 & $\mathrm{H}$ & 0.007 & 111 & $\mathrm{~L}$ & 9 & $\mathrm{HL}^{*}$ \\
\hline Uganda & 85.6 & 27 & $\mathrm{H}$ & 0.010 & 101 & $\mathrm{~L}$ & 2 & $\mathrm{HL}^{*}$ \\
\hline Lesotho & 82.6 & 29 & $\mathrm{H}$ & 0.020 & 75 & M & 0 & $\mathrm{HM}$ \\
\hline Togo & 78.7 & 30 & $\mathrm{H}$ & 0.002 & 123 & $\mathrm{~L}$ & 4 & $\mathrm{HL}^{*}$ \\
\hline Mauritania & 77.9 & 31 & $\mathrm{H}$ & 0.007 & 113 & $\mathrm{~L}$ & 5 & $\mathrm{HL}^{*}$ \\
\hline Tanzania & 77.9 & 31 & $\mathrm{H}$ & 0.038 & 39 & $\mathrm{H}$ & 6 & $\mathrm{HH}^{*}$ \\
\hline Swaziland & 77.1 & 33 & $\mathrm{H}$ & 0.001 & 124 & $\mathrm{~L}$ & 0 & $\mathrm{HL}$ \\
\hline Cambodia & 76.4 & 34 & $\mathrm{H}$ & 0.052 & 22 & $\mathrm{H}$ & 9 & $\mathrm{HH}^{*}$ \\
\hline Pakistan & 75.9 & 35 & $\mathrm{H}$ & 0.010 & 103 & $\mathrm{~L}$ & 3 & $\mathrm{HL}^{*}$ \\
\hline Tajikistan & 75.5 & 36 & $\mathrm{H}$ & 0.025 & 65 & M & 0 & $\mathrm{HM}$ \\
\hline Haiti & 73.2 & 37 & $\mathrm{H}$ & 0.011 & 99 & $\mathrm{~L}$ & 8 & $\mathrm{HL}^{*}$ \\
\hline Comoros & 71.7 & 38 & $\mathrm{H}$ & 0.017 & 82 & M & 0 & HM \\
\hline Yemen, Rep. & 71.4 & 39 & $\mathrm{H}$ & 0.025 & 64 & M & 12 & $\mathrm{HM}^{*}$ \\
\hline Kenya & 70 & 40 & $\mathrm{H}$ & 0.052 & 21 & $\mathrm{H}$ & 5 & $\mathrm{HH}^{*}$ \\
\hline Congo, Rep. & 69.5 & 41 & $\mathrm{H}$ & 0.014 & 87 & $\mathrm{~L}$ & 0 & $\mathrm{HL}$ \\
\hline Gambia, The & 67 & 42 & $\mathrm{H}$ & 0.010 & 102 & $\mathrm{~L}$ & 3 & $\mathrm{HL}^{*}$ \\
\hline Senegal & 67 & 42 & $\mathrm{H}$ & 0.027 & 60 & M & 3 & $\mathrm{HM}^{*}$ \\
\hline Madagascar & 66.8 & 44 & $\mathrm{H}$ & 0.021 & 73 & M & 3 & $\mathrm{HM}^{*}$ \\
\hline Sudan & 66.6 & 45 & $\mathrm{H}$ & 0.034 & 48 & M & 3 & $\mathrm{HM}^{*}$ \\
\hline India & 64.2 & 47 & $\mathrm{H}$ & 0.054 & 19 & $\mathrm{H}$ & 2 & $\mathrm{HH}^{*}$ \\
\hline Ghana & 63.8 & 48 & $\mathrm{H}$ & 0.029 & 56 & M & 3 & $\mathrm{HM}^{*}$ \\
\hline Eritrea & 63.5 & 49 & $\mathrm{H}$ & 0.086 & 10 & $\mathrm{H}$ & 1 & $\mathrm{HH}^{*}$ \\
\hline Zimbabwe & 62.8 & 50 & $\mathrm{H}$ & 0.032 & 50 & M & 5 & $\mathrm{HM}^{*}$ \\
\hline
\end{tabular}




\begin{tabular}{|c|c|c|c|c|c|c|c|c|}
\hline Bangladesh & 62 & 51 & $\mathrm{H}$ & 0.028 & 59 & M & 0 & $\mathrm{HM}$ \\
\hline Nepal & 61.8 & 52 & $\mathrm{H}$ & 0.022 & 70 & M & 2 & $\mathrm{HM}^{*}$ \\
\hline Myanmar & 61.5 & 53 & $\mathrm{H}$ & 0.051 & 23 & $\mathrm{H}$ & 0 & $\mathrm{HH}$ \\
\hline Gabon & 60.3 & 54 & $\mathrm{H}$ & 0.041 & 33 & $\mathrm{H}$ & 0 & $\mathrm{HH}$ \\
\hline Bolivia & 59.1 & 57 & $\mathrm{H}$ & 0.018 & 81 & M & 0 & $\mathrm{HM}$ \\
\hline Turkmenistan & 58.7 & 58 & $\mathrm{H}$ & 0.040 & 34 & $\mathrm{H}$ & 1 & $\mathrm{HH}^{*}$ \\
\hline Azerbaijan & 56.7 & 59 & $\mathrm{H}$ & 0.003 & 118 & $\mathrm{~L}$ & 0 & HL \\
\hline Papua New Guinea & 54 & 60 & $\mathrm{H}$ & 0.061 & 17 & $\mathrm{H}$ & 0 & $\mathrm{HH}$ \\
\hline South Africa & 52.3 & 61 & $\mathrm{H}$ & 0.073 & 14 & $\mathrm{H}$ & 1 & $\mathrm{HH}^{*}$ \\
\hline Uzbekistan & 51 & 62 & $\mathrm{H}$ & 0.004 & 116 & $\mathrm{~L}$ & 0 & $\mathrm{HL}$ \\
\hline Botswana & 50.5 & 63 & $\mathrm{H}$ & 0.038 & 41 & $\mathrm{H}$ & 3 & $\mathrm{HH}^{*}$ \\
\hline Mongolia & 48.6 & 65 & M & 0.056 & 18 & $\mathrm{H}$ & 0 & $\mathrm{MH}$ \\
\hline Namibia & 48.2 & 66 & M & 0.035 & 46 & M & 3 & $M M^{*}$ \\
\hline Morocco & 44.2 & 67 & M & 0.042 & 32 & $\mathrm{H}$ & 1 & $\mathrm{MH}^{*}$ \\
\hline Kyrgyz Republic & 40.6 & 70 & M & 0.008 & 105 & $\mathrm{~L}$ & 0 & ML \\
\hline Guyana & 38.9 & 71 & M & 0.015 & 85 & M & 0 & MM \\
\hline Algeria & 38.8 & 72 & M & 0.018 & 79 & M & 0 & MM \\
\hline Indonesia & 37.6 & 74 & M & 0.038 & 40 & $\mathrm{H}$ & 0 & $\mathrm{MH}$ \\
\hline Guatemala & 37.2 & 75 & M & 0.019 & 78 & M & 0 & $\mathrm{MM}$ \\
\hline Kazakhstan & 36.5 & 76 & M & 0.013 & 94 & $\mathrm{~L}$ & 0 & ML \\
\hline Egypt, Arab Rep. & 35.6 & 77 & M & 0.053 & 20 & $\mathrm{H}$ & 0 & $\mathrm{MH}$ \\
\hline Iran, Islamic Rep. & 35.3 & 78 & M & 0.023 & 69 & M & 0 & MM \\
\hline Iraq & 34.4 & 81 & M & 0.236 & 1 & $\mathrm{H}$ & 0 & $\mathrm{MH}$ \\
\hline Nicaragua & 34.1 & 82 & M & 0.049 & 27 & $\mathrm{H}$ & 0 & $\mathrm{MH}$ \\
\hline Dominican Republic & 31.3 & 84 & M & 0.085 & 11 & $\mathrm{H}$ & 0 & $\mathrm{MH}$ \\
\hline Brazil & 31.2 & 85 & M & 0.070 & 15 & $\mathrm{H}$ & 6 & $\mathrm{MH}^{*}$ \\
\hline Peru & 29.8 & 88 & M & 0.049 & 26 & $\mathrm{H}$ & 0 & $\mathrm{MH}$ \\
\hline Philippines & 29.4 & 90 & M & 0.038 & 38 & $\mathrm{H}$ & 0 & $\mathrm{MH}$ \\
\hline Paraguay & 29 & 91 & M & 0.012 & 98 & $\mathrm{~L}$ & 1 & $M L *$ \\
\hline Honduras & 28.8 & 92 & M & 0.026 & 61 & M & 0 & $\mathrm{MM}$ \\
\hline China & 28.8 & 92 & M & 0.176 & 4 & $\mathrm{H}$ & 2 & $\mathrm{MH}^{*}$ \\
\hline Turkey & 28.4 & 95 & M & 0.012 & 95 & $\mathrm{~L}$ & 0 & ML \\
\hline Ecuador & 28.1 & 97 & M & 0.046 & 30 & $\mathrm{H}$ & 0 & $\mathrm{MH}$ \\
\hline El Salvador & 28 & 98 & M & 0.010 & 100 & $\mathrm{~L}$ & 0 & ML \\
\hline Armenia & 26.3 & 99 & M & 0.026 & 63 & M & 0 & MM \\
\hline Vietnam & 26.2 & 100 & M & 0.082 & 12 & $\mathrm{H}$ & 0 & $\mathrm{MH}$ \\
\hline Tunisia & 24.7 & 101 & M & 0.030 & 54 & M & 1 & $\mathrm{MM}^{*}$ \\
\hline Mexico & 24.1 & 102 & M & 0.028 & 58 & M & 0 & $\mathrm{MM}$ \\
\hline Jordan & 23.9 & 103 & M & 0.026 & 62 & M & 0 & $\mathrm{MM}$ \\
\hline Albania & 23.3 & 104 & M & 0.089 & 9 & $\mathrm{H}$ & 0 & $\mathrm{MH}$ \\
\hline Romania & 23.2 & 105 & M & 0.009 & 104 & $\mathrm{~L}$ & 0 & ML \\
\hline Libya & 21.5 & 107 & M & 0.007 & 112 & $\mathrm{~L}$ & 0 & ML \\
\hline Colombia & 21.1 & 109 & M & 0.021 & 72 & M & 4 & $\mathrm{MM}^{*}$ \\
\hline Venezuela, RB & 19 & 116 & M & 0.050 & 25 & $\mathrm{H}$ & 7 & $\mathrm{MH}^{*}$ \\
\hline
\end{tabular}




\begin{tabular}{|c|c|c|c|c|c|c|c|c|}
\hline Argentina & 18.1 & 119 & M & 0.034 & 47 & M & 2 & $\mathrm{MM}^{*}$ \\
\hline Russian Federation & 17.8 & 120 & M & 0.033 & 49 & M & 3 & $\mathrm{MM}^{*}$ \\
\hline Bulgaria & 17.7 & 121 & M & 0.030 & 55 & M & 0 & $\mathrm{MM}$ \\
\hline Saudi Arabia & 17.6 & 123 & M & 0.121 & 8 & $\mathrm{H}$ & 0 & $\mathrm{MH}$ \\
\hline Sri Lanka & 16.4 & 125 & $\mathrm{~L}$ & 0.153 & 5 & $\mathrm{H}$ & 0 & LH \\
\hline Lebanon & 16.3 & 127 & $\mathrm{~L}$ & 0.042 & 31 & $\mathrm{H}$ & 0 & LH \\
\hline Ukraine & 15.9 & 128 & $\mathrm{~L}$ & 0.000 & 127 & $\mathrm{~L}$ & 0 & LL \\
\hline Thailand & 15.9 & 128 & $\mathrm{~L}$ & 0.225 & 2 & $\mathrm{H}$ & 1 & $\mathrm{LH}^{*}$ \\
\hline Uruguay & 14.8 & 132 & $\mathrm{~L}$ & 0.013 & 93 & $\mathrm{~L}$ & 0 & LL \\
\hline Macedonia, FYR & 14.3 & 134 & $\mathrm{~L}$ & 0.000 & 128 & $\mathrm{~L}$ & 0 & LL \\
\hline Costa Rica & 11 & 142 & $\mathrm{~L}$ & 0.032 & 51 & M & 0 & LM \\
\hline Belarus & 10.9 & 144 & $\mathrm{~L}$ & 0.124 & 7 & $\mathrm{H}$ & 0 & LH \\
\hline Slovak Republic & 9.9 & 149 & $\mathrm{~L}$ & 0.023 & 68 & M & 0 & LM \\
\hline Hungary & 9.5 & 150 & $\mathrm{~L}$ & 0.024 & 66 & M & 0 & LM \\
\hline Chile & 9.1 & 152 & $\mathrm{~L}$ & 0.014 & 91 & $\mathrm{~L}$ & 0 & $\mathrm{LL}$ \\
\hline Poland & 8.3 & 155 & $\mathrm{~L}$ & 0.012 & 96 & $\mathrm{~L}$ & 0 & LL \\
\hline Croatia & 7.3 & 157 & $\mathrm{~L}$ & 0.003 & 120 & $\mathrm{~L}$ & 0 & $\mathrm{LL}$ \\
\hline United States & 7.1 & 159 & $\mathrm{~L}$ & 0.018 & 80 & M & 1 & $\mathrm{LM}^{*}$ \\
\hline Greece & 6.8 & 160 & $\mathrm{~L}$ & 0.046 & 29 & $\mathrm{H}$ & 0 & $\mathrm{LH}$ \\
\hline Cuba & 6.6 & 161 & $\mathrm{~L}$ & 0.017 & 83 & M & 2 & $\mathrm{LM}^{*}$ \\
\hline New Zealand & 6 & 163 & $\mathrm{~L}$ & 0.002 & 122 & $\mathrm{~L}$ & 1 & $\mathrm{LL}^{*}$ \\
\hline Ireland & 5.8 & 164 & $\mathrm{~L}$ & 0.003 & 121 & $\mathrm{~L}$ & 1 & $\mathrm{LL}^{*}$ \\
\hline United Kingdom & 5.6 & 165 & $\mathrm{~L}$ & 0.022 & 71 & M & 1 & $\mathrm{LM}^{*}$ \\
\hline Czech Republic & 5.6 & 165 & $\mathrm{~L}$ & 0.028 & 57 & M & 0 & LM \\
\hline Spain & 5.5 & 168 & $\mathrm{~L}$ & 0.031 & 53 & M & 0 & LM \\
\hline Portugal & 5.5 & 168 & $\mathrm{~L}$ & 0.037 & 42 & $\mathrm{H}$ & 0 & LH \\
\hline Liechtenstein & 5.3 & 171 & $\mathrm{~L}$ & 0.000 & 129 & $\mathrm{~L}$ & 0 & LL \\
\hline Canada & 5.3 & 171 & $\mathrm{~L}$ & 0.047 & 28 & $\mathrm{H}$ & 3 & $\mathrm{LH}^{*}$ \\
\hline Netherlands & 5.1 & 173 & $\mathrm{~L}$ & 0.003 & 119 & $\mathrm{~L}$ & 0 & LL \\
\hline Australia & 5.1 & 173 & $\mathrm{~L}$ & 0.067 & 16 & $\mathrm{H}$ & 0 & LH \\
\hline Italy & 4.8 & 176 & $\mathrm{~L}$ & 0.040 & 35 & $\mathrm{H}$ & 1 & $\mathrm{LH}^{*}$ \\
\hline Switzerland & 4.7 & 177 & $\mathrm{~L}$ & 0.012 & 97 & $\mathrm{~L}$ & 0 & LL \\
\hline Denmark & 4.6 & 180 & $\mathrm{~L}$ & 0.007 & 110 & $\mathrm{~L}$ & 0 & $\mathrm{LL}$ \\
\hline Austria & 4.6 & 180 & $\mathrm{~L}$ & 0.020 & 77 & M & 0 & LM \\
\hline Slovenia & 4.5 & 182 & $\mathrm{~L}$ & 0.014 & 88 & $\mathrm{~L}$ & 0 & LL \\
\hline Germany & 4.4 & 183 & $\mathrm{~L}$ & 0.015 & 86 & M & 0 & LM \\
\hline France & 4.4 & 183 & $\mathrm{~L}$ & 0.051 & 24 & $\mathrm{H}$ & 1 & $\mathrm{LH}^{*}$ \\
\hline Norway & 3.8 & 188 & $\mathrm{~L}$ & 0.020 & 76 & M & 0 & LM \\
\hline Finland & 3.5 & 189 & $\mathrm{~L}$ & 0.004 & 114 & $\mathrm{~L}$ & 0 & $\mathrm{LL}$ \\
\hline Sweden & 3.4 & 190 & $\mathrm{~L}$ & 0.040 & 37 & $\mathrm{H}$ & 0 & LH \\
\hline Japan & 3.3 & 191 & $\mathrm{~L}$ & 0.001 & 126 & $\mathrm{~L}$ & 0 & LL \\
\hline Iceland & 3 & 192 & $\mathrm{~L}$ & 0.000 & 129 & $\mathrm{~L}$ & 1 & $\mathrm{LL}^{*}$ \\
\hline
\end{tabular}

